\title{
Isolated hypoplastic circumflex coronary artery: a rare cause of haemorrhagic myocardial infarction in a young athlete
}

Florian-Nikolaus Riede ${ }^{1}$, Stefan Bulla ${ }^{2}$, Sebastian Grundmann ${ }^{3}$, Martin Werner ${ }^{4}$, Urs-Nikolaus Riede ${ }^{4}$ and Claudia Otto ${ }^{4^{*}}$

\begin{abstract}
Hypoplastic coronary artery disease is a rare condition that may lead to myocardial infarction and sudden death. Here we describe for the first time an isolated hypoplasia of the left circumflex artery (LCX). An otherwise healthy and athletically active 16-year-old boy was admitted to the intensive care unit (ICU) after out-of-hospital cardiac arrest. He died 12 hours after the initial event. Autopsy revealed an isolated hypoplastic LCX and acute haemorrhagic infarction in the posterolateral myocardium. The existence of isolated hypoplasia of the LCX challenges our understanding of coronary artery development.

Virtual slides: The virtual slide(s) for this article can be found here: http://www.diagnosticpathology.diagnomx.eu/ vs/1558483061962648
\end{abstract}

Keywords: Isolated hypoplasia of the left circumflex artery, Myocardial haemorrhagic infarction, Sudden death in young athletes, Coronary artery development

\section{Background}

Congenital coronary artery anomalies are rare, affecting approximately $1 \%$ of the general population [1-6]. They are often an incidental finding in asymptomatic patients [1,5-8]. They occur in $1 \%$ of all congenital heart disease and manifest a wide variety of disorders [9-23]. Some, such as the anomalous location of a coronary ostium $[22,24]$ the duplication of coronary arteries, a single coronary artery [18] or multiple coronary ostia [25], become clinically significant only when another surgical cardiac procedure becomes necessary; surgical correction is not generally required in these patients. Approximately $20 \%$ of coronary anomalies can lead to life-threatening complications, including myocardial infarction, arrhythmia, or sudden death early in life or during adulthood [21,22,26,27]. On the other hand, the diagnosis of an anomalous origin of the left coronary artery from the pulmonary artery or from the opposite sinus with an inter-arterial course is an indication for surgery. Some anomalies like coronary

\footnotetext{
* Correspondence: claudia.otto@uniklinik-freiburg.de

${ }^{4}$ Department of Pathology, University Hospital Freiburg, i. Br., Breisacherstr. 115a, D-79106 Freiburg i. Br., Germany

Full list of author information is available at the end of the article
}

artery fistulas, myocardial bridging, and coronary aneurysm require surgery only when they cause clinical symptoms $[28,29]$.

Hypoplastic coronary artery disease (HCAD) was first reported in 1970. It occurs rarely and refers to the underdevelopment of one or both coronary arteries or their main branches [20,22,27,30-32]. Hypoplasia of the left circumflex coronary artery is a genuine rarity $[7,33]$ On the basis of angiography, coronary artery anomalies are classified in seven patterns $[19,20]$. Most of the affected patients were young adults and experienced sudden cardiac death without antecedent symptoms [8,34]. Diagnosis is often made at autopsy $[8,24,26,35]$.

We hereby present the case of sudden death in a 16-year-old healthy Caucasian male who was physically active and participated in sports including competitive mountain-biking. There was no remarkable medical history. This is the first description of an isolated hypoplasia of a coronary artery branch with no other abnormalities of the other coronary arteries or concomitant congenital heart disease.

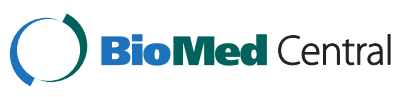




\section{Case presentation}

A 16-year-old male was admitted to the intensive care unit of our university hospital after out-of-hospital cardiac arrest. While riding his bicycle through the city center, he suddenly collapsed and when he failed to regain consciousness, cardiopulmonary resuscitation was immediately initiated by bystanders and sustained until the arrival of a medical response team 10 minutes later. The initiallydetected heart rhythm revealed ventricular fibrillation and cardiopulmonary resuscitation was continued according to current guidelines including intubation, a total of eleven biphasic shocks and a fractionated total dose of $600 \mathrm{mg}$ amiodarone until a stable sinus rhythm could be maintained. However, the patient remained pulse-less, so systemic fibrinolysis was initiated by infusing 8000 units of tenecteplase. Therapeutic hypothermia was induced by the infusion of cold saline solution and he was transported under continuous ventilation and chest compression to our hospital's ICU, where he arrived 56 minutes after the initial event.

Upon admission, emergency echocardiography ruled out pericardial effusion, however, it showed a severely reduced left ventricular ejection fraction as the reason for the persistent electromechanical dissociation. Because of the known positive predictors for a promising neurological outcome (immediate initiation of bystander-CPR and young age), a pump-driven extracorporal membrane oxygenator was implanted by cannulating the femoral vein and artery during continuous CPR, and he eventually became haemodynamically and respiratorily stable.

Clinical examination of the now stable patient was unremarkable other than the right pupil's being dilated and unresponsive to light. Due to this finding and his low cardiovascular risk profile, coronary angiography was postponed to perform a head and body high resolution contrast CT, including visualisation of the coronary anatomy. The main findings of the cardio-CT were a rarefication of the left coronary circumflex with normal anatomy of the left anterior descending (LAD) and a prominent right coronary artery (Figure 1). Unfortunately, computed tomography of the head (CCT) imaging also displayed already extensive, diffuse, cerebral oedema with herniation and brain stem compression. Cerebrovascular Doppler-imaging revealed little residual cerebral perfusion. Shortly thereafter, the patient suffered an extensive pulmonary haemorrhage, and his blood pressure could not be stabilized. Once extracorporal circulation was discontinued, the patient was declared dead twelve hours after the initial event.

Initial laboratory testing showed a normal blood count besides a mild thrombocytopenia. Before the event, the patient was well and had no medical history besides a syncopal fall 3 years earlier. There was no family history of sudden cardiac or unexplained death.

Postmortem examination was performed as described by $\mathrm{H}$. Hamperl [36]. The heart was dissected, yielding tangential and transversal transsections, and preserved in formalin for further examination. Tissue sections were stained with hematoxilin/eosin and Elastica van Gieson, as well as with PAS to stain the microthrombi, and Luxol fast blue to stain the ischaemic lesions $[37,38]$. The necrotic cardiomyocytes were immunohistochemically stained with a monoclonal antibody to C4d (C4d/TK; dilution m1:10, Biozol, Eching, Germany), the cardiomyocytic cellular membrane (sarkolemma) as well as the Z-band were stained with a monoclonal antibody to CD56 (C56/TK; dilution m1:10, Biozol, Eching, Germany) and the myocardial capillaries were stained with the monoclonal antibody CD34(C56/TK; dilution m1:10, Biozol, Eching, Germany) in an Autostainer 9421 (DAKO) according to the manufacturer's instruction [39-42]. The coronary diameter was measured by a fixed threshold method from the transverse sections obtained along the long-axis of each coronary artery $[12,15]$ after fixation of the heart with formalin.

Initial computed tomography of the head (CCT) and the heart were performed after a pump-driven extracorporal membrane oxygenator was implanted. First, spiral CT of
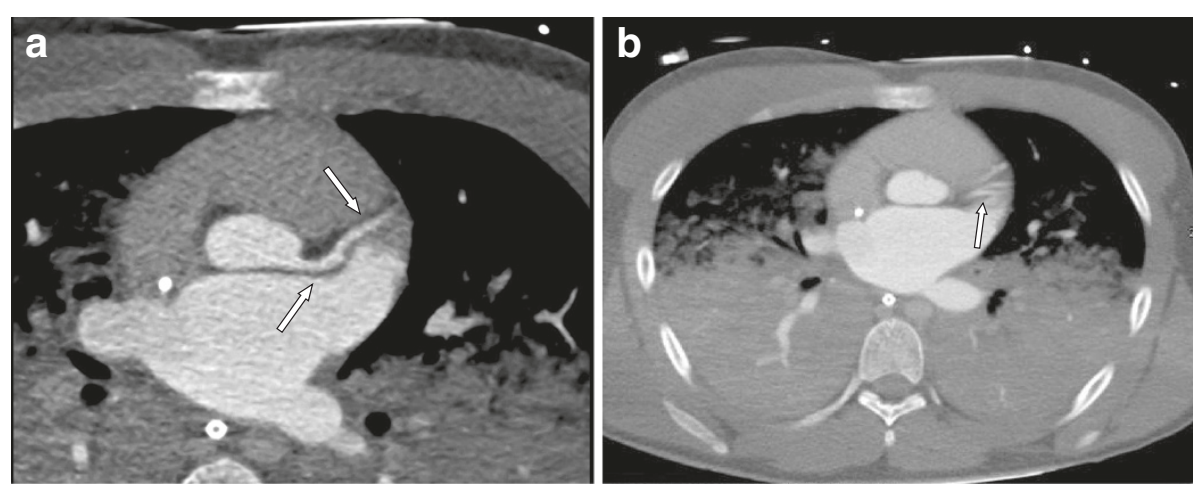

Figure 1 Segment V, VI (a) and IX (b) are shown by computed tomography. The outlet of the LCX is not presentable. Lower lobes are atelectatic and signs of pulmonary edema are visible. 
the head was performed without application of contrast agent, to detect a potential intracranial haemorrhage, edema or ischemia. Afterwards ECG-gated contrast enhanced Cardio-CT was performed in standard-technique $[43,44]$. To obtain a high opacification of the coronary arteries bolus tracking was applied. This means a repetitive measuring of threshold in an interval of 1 second in a region of interest placed in the ascending aorta (ROI), data acquisition was started $6 \mathrm{~s}$ after a threshold of 90 Hounsfield units (HU) was reached. Cardio-CT images were transferred to a workstation to generate images in additional orientations and 3D images (Figure 2).

At autopsy of the boy's heart (body weight $87 \mathrm{~kg}$, body length $189 \mathrm{~cm}$ ), it weighed $280 \mathrm{~g}$. His right coronary had a diameter of $4.5 \mathrm{~mm}$ without dominance of the left coronary artery. The left coronary artery originated from the left coronary sinus of the aorta with a single initial trunk. The left coronary artery revealed an average diameter of 4.5 $\mathrm{mm}$ and gave rise to the left anterior descending artery with a diameter of $4.3 \mathrm{~mm} ; 5.1 \mathrm{~cm}$ behind the left coronary ostium, the LAD provided a single left circumflex coronary artery, showing a diameter of under $1 \mathrm{~mm}$, a reduced length of $2.3 \mathrm{~cm}$ and a thin hypoplastic media $[4,9]$ (Figure 3). The LCX provided no origin to different branches [15] along its truncated course. Histologically there were neither signs of previous thrombosis nor vascular inflammation. Preparation of all coronary arteries revealed neither fatty streaks nor sclerosis.

Macroscopically, the heart presented a slightly hypertrophic left ventricle. Areas of haemorrhagic myocardial

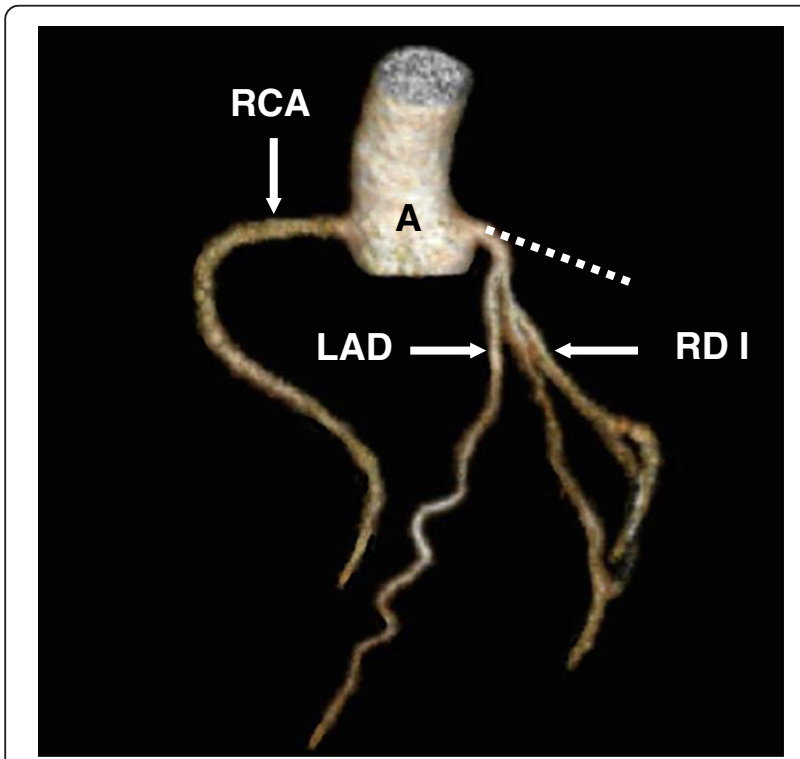

Figure 2 Volumen rendering technique shows aortic root $(A)$, RCA, LAD and ramus diagonalis I (RD I). Hypoplastic LCX is not visible, the ordinary position of the LCX is marked as a dotted line.

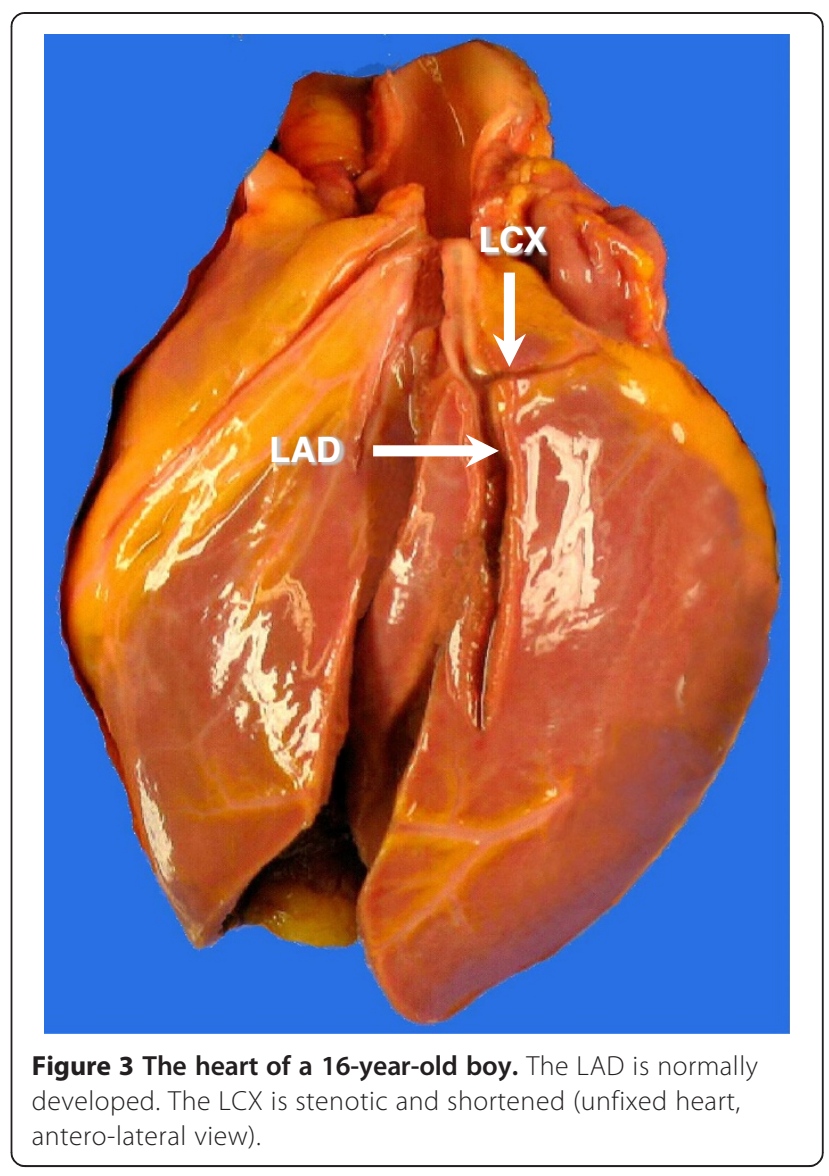

infarction were visible in the lateral wall (measuring $5 \mathrm{~cm} \times$ $7 \mathrm{~cm}$ ) and in the left ventricle's posterior wall (measuring $4 \mathrm{~cm} \times 3 \mathrm{~cm}$ ) (Figure 4). Histology revealed cardiomyocytes with contracting band necrosis und necrotic cardiomyocytes without nuclei and obvious cardiomyocytic waving in the border area. This necrotic zone was on the border of vital muscle demarcated by leucocytes. The myocardial capillaries stained with CD34 in the left ventricle's posterior wall revealed a smaller diffusion distance to the nearest capillary compared with the vital myocardium of the anterior left ventricular wall [15]. Analogously, the cardiomyocytes in the posterolateral wall were much smaller in diameter and located far apart from one another. The expression of CD56 revealed a pericellular pattern. In addition to these cardiac findings, the small and large intestines were distended and totally infarcted.

\section{Conclusions}

Autopsy of this 16-year-old athlete showed a posterolateral myocardial infarction in a focus of ischaemic cardiomyopathy. This infarction was provoked by isolated hypoplasia of the LCX with significant shortening.

In the LCX's supply area, the cardiomyocytes were reduced in size and disassociated. They revealed a pericellular 

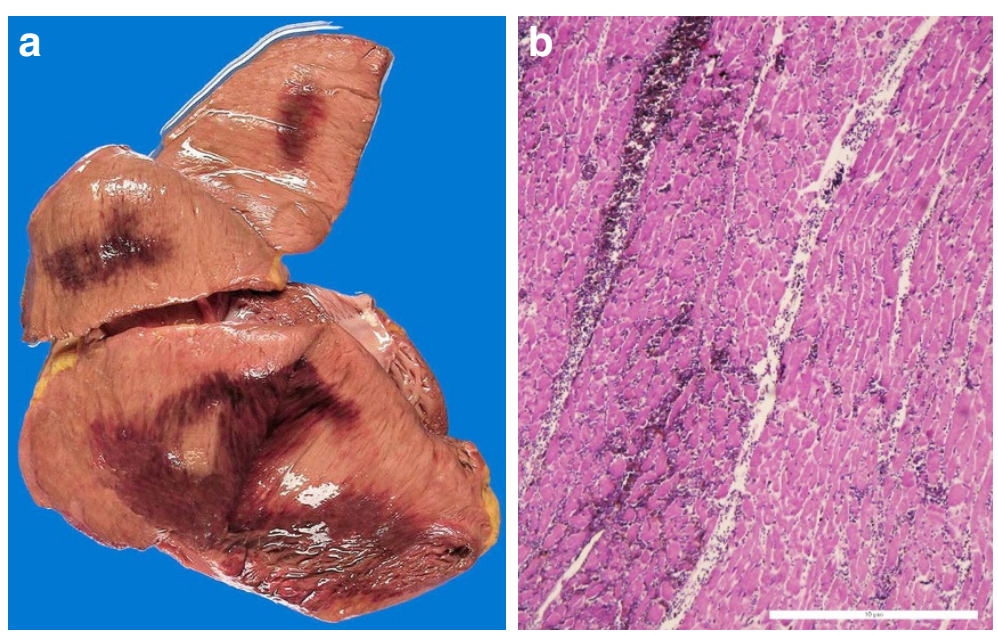

Figure 4 Fresh haemorrhagic areas visible on tangential slices through the posterior wall of the left ventricle: a) macroscopic aspect in the unfixed heart, b) histological aspect in H\&E staining $(4 \times)$.

expression pattern for CD56 typical of ischaemia-related intercellular loosening of the cardiomyocytic bond characteristic of ischaemic cardiomyopathy [39,40]. This led us to conclude that the stenotic LCX hypoplasia must have existed for quite some time, leading to a mildly hypoplastic left ventricle and focal ischaemic cardiomyopathy. As we observed no atherosclerotic lesions in the hypoplastic LCX, we assume that congenital hypoplasia was responsible for the stenosis and shortened LCX. The fact that hypoplastic coronary arteries have both a small luminal diameter (usually $<1 \mathrm{~mm}$ ) and reduced length supports this assumption [14].

The myocardial infarction was haemorrhagic and surrounded by an alterative myocarditis. That means that the infarction of the myocardium was due to an ischaemic period longer than $24 \mathrm{~h}$, leading to cardiogenic shock and to an acute infarction of the intestine and consecutive ileus.

Haemorrhagic myocardial infarctions are rare. Intramyocardial hemorrhage often occurs in conjunction with reperfusion $[18,19,24]$. Studies on dogs have shown that if reperfusion is instituted less than 20 minutes after a coronary occlusion, myocardial blood flow, function and histology return to normal. However, if 40 minutes or more elapse before blood flow is restored, normal perfusion may not be restored and histology may fail to recover $[45,46]$. In our case, the haemorrhagic myocardial infarction can be attributed to the 56-minute interval after the initial event in addition to the fibrinolysis [45-47].

The etiology of the HCAD is still unknown [48-52], though it is postulated that it results from various conditions, including stenosis of the coronary artery orifice, an aberrant course between the pulmonary artery and aorta, a coronary artery ostium in ectopic position; there is also the hypothesis of a stenosis of the coronary ostium $[22,23,25,32]$. Since the boy's autopsy revealed both a non-stenotic coronary ostia and thin coronary vessel wall with hypoplasia of the media layer, we speculate that an abnormal proliferative response by angiogenetic cells in the coronary artery (i.e. LCX) may be involved in the pathogenesis of this disease [30] rather than coronary artery spasm reflecting abnormal vasodilatory mechanisms and endothelial dysfunction [33,52]. Mice with an endothelial nitric oxid synthase (NOS3) genetic deficit provide a molecular basis with which to explain HCAD. The NOS3 deficiency results in a condition mirroring HCAD in humans [53]. Recent experiments suggest that NOS3 promotes normal coronary artery development via increases in the expression of transcription and growth factors (such as VEGF, bFGF, EPO) and the migration of epicardium-derived cells into the myocardium [53]. Other studies have shown that an increased risk of congenital heart disease, especially conotruncal heart defects, is associated via a reduction in the NOS3 activity induced by a common $894 \mathrm{G}>\mathrm{T}$ single nucleotide polymorphism [54]. In addition, environmental factors and maternal conditions including psychological stress, diabetes mellitus and hypertension, which decrease NOS3 expression and/or activity, are associated with the increased risk of congenital heart disease [53-55]. These factors together with our findings from this case lead us to this hypothesis as to the etiology of isolated LCX hypoplasia:

1. Myocardial angiogenesis was influenced at a very late stage of heart development, thus the left ventricle and LAD could develop normally, while the LCX became hypoplastic and shortened;

2. Myocardial angiogenesis proceeded in certain morphogenetic fields of the heart at different periods of time. 


\section{Consent}

Written informed consent was obtained from the parents of the patient for publication of this Case Report and any accompanying images. A copy of the written consent is available for review by the Editor-in-Chief of this journal.

\section{Abbreviations}

CCT: Computed tomography of the head; CPR: Cardiopulmonary resucitation; HCAD: Hypoplastic coronary artery disease; ICU: Intensive care unit; LAD: Left anterior descending coronary artery; NOS3: Endothelial nitric oxid synthase; LCX: Left circumflex artery.

\section{Competing interests}

There are no financial and non-financial interests to declare in relation to this manuscript.

\section{Authors' contributions}

FNR participated in the sequence alignment and drafted the manuscript. SB carried out the radiological analysis of the case to be published. SG provided the clinical information of the case to be published. MW carried out the final approval of the version to be published. UNR conceived of the study and participated in its design and coordination. CO carried out the autopsy and the histological analysis of the case presented; she also participated in the drafting of the manuscript. All authors read and approved the final manuscript.

\section{Author details}

'Department of Cardiology, University Hospital Basel, Petersgraben 3, $\mathrm{CH}-4031$ Basel, Switzerland. ${ }^{2}$ Department of Diagnostic Radiology, University Hospital Freiburg, i. Br., Hugstetterstr. 55, D-79106 Freiburg i. Br., Germany. ${ }^{3}$ Department of Internal Medicine, University Hospital Freiburg, i. Br., Hugstetterstr. 55, D-79106 Freiburg i. Br., Germany. ${ }^{4}$ Department of Pathology, University Hospital Freiburg, i. Br., Breisacherstr. 115a, D-79106 Freiburg i. Br., Germany.

Received: 9 April 2013 Accepted: 15 May 2013

Published: 6 June 2013

\section{References}

1. Gosh P, Chauhan A: Rare variant of an anomalous left coronary artery. Texas Heart Inst J 2012, 39:63-64.

2. Hauser M: Congenital anomalies of the coronary arteries. Heart 2005, 91:1240-1245.

3. Kim SY, Seo JB, Do KH, Heo JN, Lee JS, Song JW, Choe JH, Kim TH, Yong HS, Song SI, Song KS, Lim TH: Coronary artery anomalies: classification and ECG-gated multidetector row CZ findings with angiographic correlation. Radiographics 2006, 26:317-333.

4. Misuraca L, Benedetti G, Petronio AS, De Carlo M, Chella P, Pieroni A, Balbarini A: Coronary artery anomalies and their cilinical relevance. Monaldi Arch Chest Dis 2011, 76:66-71.

5. Wick R, Otto S, Byard RW: Is right coronary hypoplasia and sudden death an underdiagnoses association? Am J Forensic Med Pathol 2007, 28:128-130.

6. Cruz C, Mclean D, Jannik M, Raggi P, Zafari AM: A rare coincidence of two coronary abnormalities in an adult. Cardiol Res Practice 2010, 10:1-4.

7. Nough $\mathrm{H}$, Asari Z: Congenital absence of left circumflex coronary artery. Iran J Med Sci 2009, 34:217-219.

8. Yamanaka O, Hobbs RE: Coronary anomalies in 12'595 patients undergoing arteriography. Cathet Cardiovasc Diagn 1990, 21:28-40.

9. Angelini P, Villason S, Chan AV: Normal and abnormalous coronary arteries in humans. In Coronary artery anomalies: A comprehensive approach. Edited by Angelini P. Philadelphia: Lippincott Williams \& Wilkins; 1999:27-150.

10. Angelini P, Velasco JA, Flamm S: Coronary anomalies: incidence, pathophysiology and clinical relevance. Circulation 2002, 105:2449-2454.

11. Baltaxe HA, Wixson D: The incidence of congenital anomalies of the coronary arteries in the adult population. Radiology 1977, 122:47-52.

12. Leta-Petracca R: Normal anatomy and congenital abnormalities of the coronary arteries. In Atlas of non-invasive coronary angiography by multidetector computed tomography. Edited by Pons-Llado GE, Leta-Petracca R. Berlin: Springer; 2006:16-42.
13. Sohn SY, Jang GY, Choi BM: Congenital atresia of the left main coronary artery in infant. J Zhejinang Univ Sci Biomed \& Biotechnol 2010, 11:539-541.

14. Levin L, Derange M, Leacche M, Balaguer J, Byrne J: Acute coronary syndrome secondary to hypoplastic left main and left descending coronary arteries. Rev Argent Cardio/ 2012, 80:157-159.

15. Ogden JA: Congenital anomalies of the coronary arteries. Am J Cardiol 1979, 25:474-479.

16. Nordon DG, Rodrigues OF: Variations on the anatomy of the coronary arteries. J Morphol Sci 2012, 29:178-181.

17. Sim DS, Jeong MH, Choi S, Yoon NS, Yoon HJ, Moon JY, Hong YJ, Kim KH, Park HW, Kim JH, Ahn Y, Cho JG, Park JC: Myocardial infarction in a young man die to a hyoplastic coronary artery. Korean Circ J 2009, 39:163-167.

18. Rigatelli GL, Franco G, Rigatelli G: Rarities in the catheterization Lab: a strange type of single coronary artery. Minerva Cardioangiol 2002, 50:153-155.

19. Rigatelli GL, Docali G, Rossi P, Bovolon D, Rossi D, Bandello A, Leonardi G, Rigatelli G: Congenital coronary anomalies angiographic classification revisited. Internat J Cardiovasc Imaging 2003, 19:361-366.

20. Rigatelli $\mathrm{GL}$, Rigatelli $\mathrm{G}$ : Congenital coronary artery anomalies in the adult: a new practical viewpoint. Clin Cardiol 2005, 28:61-65.

21. Collins KA, McConell E: Sudden unexpected death resulting from an anomalous hypoplastic left coronary artery. J Forensic Sci 1998, 43:708-711.

22. Saji T, Yamamoto K, Hasiguchi R, Matsuo N, Yabe Y: Hypoplastic left coronary artery in association with occlusive intimal thickening of a coronary artery with ectopic ostium and with atresia od the left coronary. Jpn Heart 1985, 26:603-612.

23. Saroli T, Gelehrter S, Gomez-Fifer CA, van der Velde ME, Bove EL, Ending GJ: Anomalies of left coronary origin affecting surgical repair of hypoplastic left heart syndrome and shone complex. Echogradiography 2088, 25:727-731.

24. Roberts WC, Glick BN: Congenital hypoplasia of both right and left coronary arteries. Am J Cardiol 1992, 70:121-123.

25. De Giorgio F, Arena V: Ostial plication: a rarely reported cause of sudden death. Diagnostic Pathol 2010, 5:15.

26. Fiss DM: Normal coronary anatomy and anatomic variation. Applied Radiol 2007, 36:14-26. Supplement.

27. McFarland CA, Svamy RSA: Hypoplastic coronary artery disease: a rare cause of sudden cardiac death and its treatment with an implantable defibrillator. J Cardiol Cases 2011, 4:e148-e151.

28. Higginson LA, White F, Hegtveit HA, Sanders TM, Bloor CM, Covell JW: Determinants of myocardial hemorrhage after coronary reperfusion in the anaesthetized dog. Circulation 1982, 65:62-69.

29. Hort W: Anatomie und Pathologie der Koronararterien. In Pathologische Anatomie des Herzens und seiner Hüllen. Edited by Hort W. Berlin: Springer; 2000:209-553. [Seifert G (Series Editor): Spezielle pathologische Anatomie, ein Lehr- und Nachschlagewerk, vol. 22/II.

30. De Giorgio F, Grassi VM, Vetrugno G, Arena V: Sudden death in a young female with an under-recognised coronary anomaly. Diagnostic Pathol 2013, 8:41

31. Menke DM, Waller BF, Pless JE: Hypoplastic coronary arteries and high take off position of the right coronary ostium. Chest 1985, 88:299-301.

32. Tomimatu H, Sawada Y, Nakazawa M, Takao A, Hiroe M: Report of a case of the hypoplastic left coronary artery with ostial stenosis due to abnormal endothelial ridge. Ped Cardiol Cardiac Surg 1987, 2:329-335.

33. Amabile N, Fraisse A, Quilici J: Hypoplastic coronary artery disease: report of one case. Heart 2005, 91:e12.

34. Taylor AJ, Rogan KM, Virmani R: Sudden cardiac death associated with isolated coronary artery anomalies. Am Coll Cardiol 1992, 20:640-645.

35. Zugibe FT, Zugibe FT Jr, Costello JT, Breithaupt MK: Hypoplastic coronary artery disease within the spectrum of sudden unexpected death in young and middle age adults. Am J Forensic Med Pathol 1993, 14:276-283.

36. Hamperl $\mathrm{H}$ : Leichenöffnung, Befund und Diagnose: eine Einführung in den pathologisch-anatomischen Seziersaal und Demonstrationskurs. Berlin: Springer; 1972

37. Kloner RA, Canote CE, Whalen DA, Jennings RB: Effect of transient period of ischemia on myocardial cells. II. Fine structure during the first few minutes of reflow. Am J Pathol 1974, 74:372-399.

38. Edston E: Evaluation of agonal artifacts in the myocardium using a combination of histological stains and immunohistochemistry. Am Forensic Med Pathol 1997, 18:163-167.

39. Gattenlöhner S, Waller C, Ertl G, Bültmann BD, Müller-Hermelink HK, Marx A: NCAM(CD56) and RUNX1(AML1) are up-regulated in human ischemic 
cardiomyopathy and a rat model of chronic cardiac ischemia. Am $J$ Pathol 2003, 163:1081-1090.

40. Gattenlöhner S, Waller C, Ertl G, Bültmann BD, Müller-Hermelink HK, Marx A: The overexpression of NCAM (CD56) in human hearts is specific for ischemic damage. Verh Dtsch Ges Pathol 2004, 88:246-251.

41. May AM, Riede FN, Riede UN: Acute subepicardial infarction associated with severe septic shock - insight in myocardial perfusion. Path Res Pract 2010, 206:401-404

42. Yasojima K, Schwab C, McGeer EG, McGeer PL: Human heart generates complement proteins that are upregulated and activated after myocardial infarction. Circ Res 1998, 83:860-869.

43. Kang DK, Park KJ, Tahk SJ, Kim SY: Relation between the left ventricular mass and the left coronary artery dimensions as determined by $16-$ channel multidetector CT: comparison between the normotensive group and the hypertensive group. J Korean Radiol Soc 2006, 54:459-468.

44. Sabarudin A, Sun Z, Yusof AK: Coronary CT angiography with singlesource and dual-source CT: comparison of image quality and radiation dose between prospective ECG-triggered and retrospective ECG-gated protocols. Int J Cardiol 2012, 22:0167-5273. (12)01340-X.

45. Fishbein MC, Y-Rit J, Lando U, Kanmatsuse K, Mercie JM, Ganz W: The relation of vascular injury and myocardial hemorrhage to necrosis after reperfusion. Circulation 1980, 62:1274-1279.

46. Fishbein MC: Reperfusion injury. Clin Cardiol 1990, 13:213-217.

47. Fujiwara $\mathrm{H}$, Onodera T, Tanaka M, Fujiwara T, Wu DJ, Kawei C, Hamashima Y: A clinicopathologic study of patients with haemorrhagic myocardial infarction treated with selective coronary thrombolysis with urikase. Circulation 1986, 73:749-757.

48. Fraisse A, Quillicy J, Canavy I, Savin B, Aubert F, Bory M: Myocardial infarction in children with hypoplastic coronary arteries. Circulation 2000, 101:1219.

49. De Giorgio F, Abbate A, Stigliano E, Capelli A, Arena V: Hypoplastic coronary artery disease causing sudden death. Report of two cases and review of the literature. Cardiovasc Pathol 2009, 19:e107-e111.

50. Mittal SR, Maheshwari M: Absent left circumflex artery and unusual right coronary artery. J Assoc Physicians India 2008, 56:711.

51. Kayalar N, Burkhart HM, Dearani JA, Cetta F, Schaff-Hartzell V: Congenital coronary anomalies and surgical treatment. Congenit Heart Diseases 2009, 4:239-251.

52. Liu Y, Lu X, Xiang FL, Pelmann RE, Gittenberger-de Groot AC, Robbins J, Feng Q: Nitric oxide synthase-3 deficiency results in hyopoplastic coronary arteries and postnatal myocardial infarction. Europ Heart J 2012, 306:1-12.

53. Heineke J, Auger-Messier M, Xu J, Oka T, Sargent MA, York A, Klevitsky R, Vaikunth S, Duncan SA, Aronow BJ, Robbins J, Crombleholm TM, Molkentin JD: Cardiomyocyte GATA4 functions as a stress-responsive regulator of angiogenesis in the murine heart. J Clin Invest 2007, 117:3198-3210.

54. van Beynum IM, Mooji C, Kapusta L, Heil S, den Heijer M, Bloom HJ: Common $894 \mathrm{G}>\mathrm{T}$ single nucleotid polymorphism in the gene coding for endothelial nitric oxidase synthase (eNOS) and risk of congenital heart defects. Clin Chem Lab Med 2008, 46:1369-1376.

55. Lissowski LA, Verheijen PM, Copel JA, Kleinmann CS, Wassink S, Visser GH, Meijboom EJ: Congenital heart disease in pregnancies complicated by maternal diabetes mellitus. Herz 2010, 35:19-26.

doi:10.1186/1746-1596-8-91

Cite this article as: Riede et al:: Isolated hypoplastic circumflex coronary artery: a rare cause of haemorrhagic myocardial infarction in a young athlete. Diagnostic Pathology 2013 8:91.

\section{Submit your next manuscript to BioMed Central and take full advantage of:}

- Convenient online submission

- Thorough peer review

- No space constraints or color figure charges

- Immediate publication on acceptance

- Inclusion in PubMed, CAS, Scopus and Google Scholar

- Research which is freely available for redistribution

Submit your manuscript at www.biomedcentral.com/submit
Ciomed Central 